\title{
Association of social capital and AIDS health literacy with AIDS risk perception in adolescents
}

Nader Rajabi Gilan ${ }^{1}$, Seyed Ramin Ghasemi ${ }^{1}$, Akram Mohamadi' ${ }^{1}$, Mehdi Khezeli ${ }^{1}$, Fatemeh Heydarpour ${ }^{1}$, Shahab Bahrami

${ }^{1}$ Social Development and Health Promotion Research Center, Health Institute, Kermanshah University of Medical Sciences, Kermanshah, Iran

${ }^{2}$ Department of Sport Management, Kermanshah Branch, Islamic Azad University, Kermanshah, Iran

\begin{abstract}
Introduction: Human immunodeficiency virus (HIV) infection has become a major health challenge in recent decades. Poor health knowledge can lead to the faster transmission of HIV in the community. This study aimed to investigate the association of social capital and acquired immunodeficiency syndrome (AIDS) health literacy with AIDS risk perception in Iranian adolescents.

Material and methods: This cross-sectional study was conducted with 354 high school students of Kermanshah city, the west part of Iran, selected by multi-stage sampling method. Respondents filled out social capital, HIV/AIDS health literacy, and AIDS risk perception questionnaires. Data were analyzed by SPSS-18 using Pearson correlation, regression, ANOVA, and independent $t$-tests.

Results: The mean age of respondents was $17.02 \pm 0.84$ years. The results of independent $t$-test showed that girls had more scores in family social capital $(p=0.009)$ and school social capital domains $(p=0.001)$.There were a moderate and significant correlations between AIDS health literacy with family social capital $(r=0.178 ; p=0.001)$ and AIDS risk perception $(r=0.317 ; p=0.009)$. Also, regression analysis showed that $12.1 \%$ of variations in AIDS risk perception were explained by several variables of the study.

Conclusions: Considering the relationship between AIDS health literacy and social capital with AIDS risk perception, it can be concluded that the increased power of visual and written analysis and understanding of adolescents, along with cohesion, respect, trust, and mutual understanding in the family, can be a protective factor against HIV disease.
\end{abstract}

HIV AIDS Rev 2021; 20, 1: 52-58

DOI: https://doi.org/10.5114/hivar.2021.105112

Key words: AIDS literacy, AIDS risk perception, social capital, adolescents.

\section{Introduction}

Human immunodeficiency virus (HIV) infection has become a major health challenge in recent decades $[1,2]$. Because of the increasing prevalence of HIV/acquired im-

Address for correspondence: Mehdi Khezeli, Social Development and Health Promotion Research Center, Kermanshah University of Medical Sciences, phone +98918934 4760,

e-mail: khezelimehdi@yahoo.com

munodeficiency syndrome (AIDS) in the world, promoting public awareness about HIV/AIDS becomes one of the major goals of the World Health Organization (WHO) in recent years [3]. If preventive programs are ignored, the virus can

Article history:

Received: 25.02.2020

Received in revised form: 19.09.2020

Accepted: 28.09.2020

Available online: 30.03 .2021
International Journal of HIV-Related Problem

HIV \& AIDS

R e vi e w 
quickly infect large number of people, and due to multiple ways of transition, it can threaten human societies from infancy to old age [4]. Considering the trends and at-risk groups, one of the most important barriers to preventive measures is the lack of adequate awareness on AIDS and its ways of transmission [5].

Researches show that many educational and informational interventions in health system are not corresponding with understanding level of the target group, and receiving information or using it requires sufficient reading, computing, and decision-making skills [6]. This mismatch has necessitated the emergence of a new concept called "health literacy". Health literacy consists of a set of reading, listening, analyzing, decision-making skills, and ability to apply these skills in health situations that are not necessarily related to education level or general reading ability [7]. Some studies show that health literacy is an important predictor of poor adherence to HIV treatment process [8]. On the other hand, poor health literacy can lead to misunderstanding of ways of transmission of HIV [9]. "Risk perception" is an individual, subjective judgment about the characteristics and severity of risk of a disease or threat. The perception process is influenced by several psychological factors as well as environmental conditions [10]. Feelings of danger and risk in individuals can lead to increased health behaviors and efforts to reduce the risk of diseases [11]. Researchers have found that the social context is the main important predictor of health and well-being. Therefore, to provide a true picture of communities' health, we need to consider socio-economic conditions of each community. Social capital is one of the social concepts that have received much attention in the field of public health [12].

Social capital, defined by variables, such as social trust, interactive norms, and social network density, has been identified as a health affecting factor [13]. The level of social capital in the family and school is especially important for adolescents because they spend most of their active time with the family and at school [14]. Families with high family social capital level spend more time and energy with their children, which make them empowered for social, psychological, and health promotion behaviors [15]. School social capital is also a factor that is shared between school environment and student experiences, including their dependence level and sense of belonging to the school. If the school fails to perform functions related to the social capital, such as appropriate socializing and fostering interpersonal relationships, the consequences of this inadequacy can lead to a lack of identity and connection with others, and weakness in adolescent dating. Such people develop a false prejudice against others and may engage in dangerous practices fearlessly [15] and participate in risky behaviors that may increase the risk of HIV infection.

Despite the importance of the AIDS issue in the society and its growing prevalence in young people and adolescents in Iran, few studies have been conducted on AIDS-related issues in Iranian adolescents. Adolescents are at a greater risk of HIV/AIDS because of some predisposing factors, includ- ing sense of curiosity, peer pressure, and lack of knowledge and skills during first sexual experiences [16]. Also, due to lack of adequate studies in Iran to investigate the role of social factors on health literacy and AIDS risk perception, this study aimed to investigate social capital and health literacy and its relationship with AIDS risk perception in high school adolescents of Kermanshah city.

\section{Material and methods}

\section{Design and procedure}

This cross-sectional study was conducted with high school students in Kermanshah, a west part of Iran. Sample size was calculated using Cochran formula as 379 participants. The samples were selected by multi-stage sampling method. In order to sample selection, each of the three education districts of Kermanshah was considered as a cluster. Then, two girls' and two boys' secondary schools were selected from each district. The sample size was selected in a proportion to the population of each education district between schools. Inclusion criteria were studying at high school of Kermanshah, signing an informed consent, not having HIV/AIDS, and not having severe mental disorders; the last criterium was examined and confirmed by a psychologist. After distribution of the study instruments, 354 valid questionnaires were finally received and analyzed (response rate of $93.4 \%)$.

\section{Data gathering}

Data collection tool was a four-part questionnaire. The first part included a checklist of demographic and contextual variables, including questions on age, gender, number of households, education grade, and parental education and occupation. The second part was a social capital questionnaire developed by Golchin, which consisted of two subscales of family and school [15]. Family social capital was assessed by 33 questions divided into five dimensions. These dimensions included family members' social relationships (6 questions), intra-family support (9 questions), satisfaction with family relationships (6 questions), parents' attention to student and school (7 questions), and parents' observation of student behavior (5 questions). The five-point Likert scale was used to answer questions (from "completely true" to "not at all"), in which a higher score indicated more social capital. School social capital sub-scale included four dimensions of participation in school collective activities (6 questions), in-school trust (4 questions), control and supervision in school (4 questions), and feeling of belonging to school (7 questions). Questions in this section were also answered in five-point Likert scale (from "very high" to "very low"), and the higher the score, the higher the level of school social capital. Reliability of school social capital has been reported as 0.77 , and its sub-scales as $0.82,0.87,0.71$, and 0.84 , respectively [15]. 
Table 1. Demographic characteristics and mean scores of research variable in students

\begin{tabular}{|c|c|c|c|c|c|c|}
\hline \multirow{2}{*}{ Variables/Category } & \multirow{2}{*}{$n(\%)$} & \multirow{2}{*}{$\begin{array}{l}\text { AIDS risk } \\
\text { perception, } \\
\text { mean (SD) }\end{array}$} & \multirow{2}{*}{$\begin{array}{l}\text { AIDS health } \\
\text { literacy, } \\
\text { mean (SD) }\end{array}$} & \multicolumn{2}{|c|}{ Social capital, mean (SD) } & \multirow{2}{*}{ Test } \\
\hline & & & & Family & School & \\
\hline \multicolumn{7}{|l|}{ Sex } \\
\hline Girls & $207(58.5)$ & $38.19(7.54)$ & $38.95(10.12)$ & $94.87(20.11)$ & $42.38(13.02)$ & \multirow{4}{*}{$t$-test } \\
\hline Boys & $147(41.5)$ & $36.95(0.84)$ & $40.51(7.98)$ & $84.92(21.78)$ & $38.73(12.54)$ & \\
\hline Total & $354(5)$ & $37.68(7.31)$ & $39.59(9.31)$ & $90.74(21.36)$ & $40.78(12.93)$ & \\
\hline$p$-value & - & 0.116 & 0.106 & 0.009 & 0.001 & \\
\hline \multicolumn{7}{|l|}{ Education grade } \\
\hline First level & $98(28.1)$ & $37.82(6.49)$ & $40.51(9.44)$ & $90.94(20.15)$ & $40.15(12.73)$ & \multirow{4}{*}{ ANOVA } \\
\hline Third level & $202(57.9)$ & $37.60(7.74)$ & $38.80(9.20)$ & $92.69(21.06)$ & $42.65(12.15)$ & \\
\hline Diploma & $49(14)$ & $38.14(7.01)$ & $41.15(9.69)$ & $83.46(23.01)$ & $35.69(15.13)$ & \\
\hline$p$-value & - & 0.892 & 0.153 & 0.025 & 0.002 & \\
\hline \multicolumn{7}{|l|}{ Father's education } \\
\hline Illiterate & $37(10.6)$ & $34.41(7.87)$ & $38.58(10.50)$ & $74.08(26.88)$ & $38.20(13.74)$ & \multirow{6}{*}{ ANOVA } \\
\hline Elementary & $69(19.7)$ & $38.50(6.42)$ & $40.18(7.52)$ & $89.59(22.30)$ & 40.05 (12.77) & \\
\hline Intermediate & $67(19.1)$ & $38.28(7.78)$ & $39.40(9.44)$ & $99.75(18.01)$ & $43.96(12.17)$ & \\
\hline Diploma & $113(32.3)$ & $37.12(7.89)$ & $39.46(9.23)$ & $90.38(18.15)$ & $41.26(12.55)$ & \\
\hline Academic & $64(18.3)$ & $38.88(5.94)$ & $40.25(10.60)$ & $92.81(20.53)$ & 39.38 (14.09) & \\
\hline$p$-value & - & 0.026 & 0.899 & 0.001 & 0.160 & \\
\hline \multicolumn{7}{|l|}{ Mother's education } \\
\hline Illiterate & $62(17.6)$ & $37.25(7.25)$ & $40.58(8.46)$ & $82.33(24.73)$ & $38.16(12.59)$ & \multirow{6}{*}{ ANOVA } \\
\hline Elementary & $93(26.4)$ & $37.68(7.34)$ & $38.82(9.40)$ & $89.51(24.37)$ & 40.89 (13.18) & \\
\hline Intermediate & $82(23.3)$ & 36.89 (6.99) & 39.50 (8.94) & $93.25(18.45)$ & 41.35 (12.17) & \\
\hline Diploma & $84(23.9)$ & $38.34(7.72)$ & $39.02(9.64)$ & 95.89 (17.72) & 43.47 (13.18) & \\
\hline Academic & $31(8.8)$ & $38.91(7.40)$ & $41.81(10.68)$ & $91.72(15.43)$ & 38.37 (13.58) & \\
\hline$p$-value & - & 0.606 & 0.492 & 0.003 & 0.113 & \\
\hline \multicolumn{7}{|l|}{ Father's job } \\
\hline Employee & $76(21.8)$ & $37.73(7.53)$ & $39.09(10.27)$ & $95.29(19.95)$ & 41.59 (13.61) & \multirow{6}{*}{ ANOVA } \\
\hline Free job & $140(40.2)$ & $37.29(7.26)$ & $40.78(8.74)$ & $90.18(20.49)$ & $41.63(12.52)$ & \\
\hline Labor & $72(20.7)$ & $38.30(7.56)$ & $39.01(9.20)$ & $91.35(25.22)$ & $39.79(14.22)$ & \\
\hline Unemployment & $18(5.2)$ & $35.62(7.80)$ & $35.97(9.48)$ & $75.40(22.63)$ & $40.95(9.85)$ & \\
\hline Retirement & $42(12.1)$ & $38.00(6.64)$ & $38.32(9.47)$ & $89.09(18.22)$ & 38.59 (12.71) & \\
\hline$p$-value & - & 0.671 & 0.185 & 0.011 & 0.648 & \\
\hline \multicolumn{7}{|l|}{ Mother's job } \\
\hline Employee & $17(4.8)$ & $38.28(6.58)$ & $41.10(12.25)$ & $98.06(13.23)$ & $38.64(13.12)$ & \multirow{3}{*}{$t$-test } \\
\hline Household & $336(95.2)$ & $37.66(7.36)$ & $39.54(9.16)$ & $90.29(21.63)$ & $40.92(12.91)$ & \\
\hline$p$-value & - & 0.734 & 0.500 & 0.144 & 0.478 & \\
\hline
\end{tabular}

The third part of the questionnaire was an AIDS health literacy scale developed and introduced by Rezai et al. [17]. This scale consisted of five sub-scales, with 13 items each rated on six-point Likert scale ranged from zero to five ("not at all", "very low", and "low" to "some extent", "high", and "very high"); for example, "written subjects about AIDS in books and journals are perceptible" - higher scores in this questionnaire indicated higher health literacy. The sub- scales Cronbach's $\alpha$ of this questionnaire were reported in a previous study as follows: reading skills $(\alpha=0.85)$, access ( $\alpha=0.65)$, understanding ( $\alpha=0.67)$, assessment ( $\alpha=0.63)$, and decision-making $(\alpha=0.69)$. The total Cronbach's $\alpha$ coefficient for this questionnaire has been reported as 0.79 [17].

The fourth section of gathering tool was AIDS risk perception scale introduced by Rezaei et al. in Persian language, and consisted of 14 questions on six-point Likert scale, 
Table 2. Pearson correlation test between the main variables of study $(n=354)$

\begin{tabular}{l|c|c|c|c|c}
\hline Variables & 1 & 2 & 3 & 4 & 5 \\
\hline 1. Total social capital & - & $0.919^{*}$ & $0.759^{*}$ & $0.236^{*}$ & $0.222^{*}$ \\
\hline 2. Family social capital & $0.919^{*}$ & - & $0.441^{*}$ & $0.178^{*}$ & $0.224^{*}$ \\
\hline 3. School social capital & $0.759^{*}$ & $0.441^{*}$ & - & 0.244 & $0.136^{*}$ \\
\hline 4. AIDS health literacy & $0.236^{*}$ & $0.178^{*}$ & $0.244^{*}$ & - & $0.317^{*}$ \\
\hline 5. AIDS risk perception & $0.222^{*}$ & $0.224^{*}$ & $0.136^{*}$ & $0.317^{*}$ & - \\
\hline${ }^{*} p<0.05$
\end{tabular}

ranged from zero to five score. In this scale, higher score indicated more risk perception about AIDS. The results for the reliability test of this questionnaire showed correlation coefficient of 0.77 between the two stages of test-retest reliability method, and the Cronbach's a of 0.77 [17].

\section{Ethical issues}

This study was approved by the Ethics Committee of Kermanshah University of Medical Sciences (No. IR.KUMS. REC.1397.218).

\section{Statistical analysis}

The data were analyzed by SPSS 18 software using descriptive statistics (mean and standard deviation) and analytical tests with independent $t$-test, one-way ANOVA, correlation coefficient, and multivariate regression.

\section{Results}

In total, 354 students with mean age of $17.02 \pm 0.84$ years participated in the present study. Mean (SD) of family member was 4.91 (1.21). More than half of participants (58.5\%) were females. The majority of student's fathers were self-employed $(40.2 \%)$ or employees $(21.8 \%)$, and the majority of students' mothers (95.2\%) were housewives. Also, more than half of the fathers (50.6\%) had a diploma or academic education, and more than half of the mothers (67.3\%) presented with under diploma education.

The normality of data (AIDS risk perception, family and school social capital, and AIDS health literacy) were confirmed using Kolmogorov-Smirnov test at a significance level higher than $5 \%$. Results of independent $t$-test showed that girls had significantly higher scores than boys in family and school social capital $(p<0.05)$. Results of ANOVA test also showed that students in third grade of high school had higher levels of family and school social capital than other educational grades $(p<0.05)$. There was a significant relationship between education of fathers and AIDS risk perception $(p=0.026)$ as well as family social capital $(p=0.001)$. Moreover, there was a significant relationship between education of mothers and family social capital $(p=0.003)$ (Table 1$)$.
Pearson correlation test showed that there was a significant inverse relationship between age and family social capital $(r=-0.112 ; p<0.05)$, while correlation of age with other main variables was not significant. The results also indicated that number of family member only had a significant inverse relationship with AIDS risk perception $(r=-0.103 ; p<0.05)$.

The results of Pearson correlation test also showed that there was a significant relationship between total social capital and AIDS risk perception $(r=0.222 ; p<0.001)$, family social capital and AIDS risk perception $(r=0.224 ; p<0.001)$ as well as school social capital and AIDS risk perception $(r=0.136 ; p<0.001)$. Furthermore, there was a significant mild relationship between AIDS health literacy and HIV/ AIDS risk perception $(r=0.317 ; p<0.001)$ (Table 2).

Stepwise linear regression analysis was performed in order to investigate the predictors of AIDS risk perception. We used Durbin-Watson statistics to assess auto-correlation of data and according to the results, auto-correlation between the data was rejected ( $\mathrm{DW}=2.10)$. In order to evaluate multicollinearity, we also used tolerance and VIF statistics in SPSS and the results showed that there was no multicollinearity between the data. As shown in Table 3, AIDS health literacy (Coef $=-0.236 ; p$-value $=0.001)$ and family social capital (Coef $=-0.046 ; p$-value $=0.032$ ) had an increasing effect on AIDS risk perception. Elementary education in fathers also predicted the higher score of AIDS risk perception compared to those who had illiterate fathers. In the final regression model, coefficient of determination $\left(R^{2}\right)$ and adjusted coefficient of determination (adj- $\left.R^{2}\right)$ were 0.76 and 0.121 , respectively.

Moreover, analysis of variance in this case indicated that the value of $F=21.313$ was significant $(p<0.001)$. Therefore, it can be said that about $12.1 \%$ of the changes in the HIV/ AIDS risk perception can be explained by AIDS health literacy, family social capital, and fathers' education level.

\section{Discussion}

The purpose of this study was to investigate the relationships between family and school social capital, AIDS health literacy and risk perception among adolescent girls and boys (high school students) in Kermanshah, Iran. The results of correlation analysis showed that there was a positive and significant relationship between social capital (family and 
Table 3. Multiple regression model of factors affecting AIDS risk perception $(n=335)$

\begin{tabular}{|c|c|c|c|}
\hline Variables/Categories & Coef $(\beta)$ & SE & $p$-value \\
\hline Sex & -1.04 & 0.898 & 0.244 \\
\hline \multicolumn{4}{|l|}{ Grade education } \\
\hline First level & \multicolumn{3}{|c|}{ Ref } \\
\hline Third level & 0.642 & 1.11 & 0.565 \\
\hline Diploma & 1.76 & 1.76 & 0.317 \\
\hline \multicolumn{4}{|l|}{ Father's education } \\
\hline Illiterate & \multicolumn{3}{|c|}{ Ref } \\
\hline Elementary & 3.19 & 1.58 & 0.044 \\
\hline Intermediate & 2.88 & 1.76 & 0.103 \\
\hline Diploma & -0.376 & 1.78 & 0.293 \\
\hline Academic & -0.140 & 2.07 & 0.137 \\
\hline \multicolumn{4}{|l|}{ Mother's education } \\
\hline Illiterate & \multicolumn{3}{|c|}{ Ref } \\
\hline Elementary & -0.348 & 1.31 & 0.792 \\
\hline Intermediate & -1.01 & 1.47 & 0.40 \\
\hline Diploma & -0.154 & 1.67 & 0.136 \\
\hline Academic & 0.672 & 2.18 & 0.482 \\
\hline \multicolumn{4}{|l|}{ Father's job } \\
\hline Employee & \multicolumn{3}{|c|}{ Ref } \\
\hline Free job & -0.109 & 1.19 & 0.927 \\
\hline Labor & 1.44 & 1.50 & 0.337 \\
\hline Unemployment & 0.799 & 2.11 & 0.705 \\
\hline Retirement & 1.11 & 1.49 & 0.456 \\
\hline \multicolumn{4}{|l|}{ Mother's job } \\
\hline \multicolumn{4}{|l|}{ Employee } \\
\hline Household & 0.414 & 2.14 & 0.847 \\
\hline Family social capital & 0.046 & 0.021 & 0.032 \\
\hline School social capital & -0.001 & 0.034 & 0.959 \\
\hline AIDS health literacy & 0.236 & 0.043 & 0.001 \\
\hline Age & -0.860 & 0.642 & 0.181 \\
\hline Family number & -0.248 & 0.357 & 0.487 \\
\hline Constant & 37.97 & 11.06 & 0.001 \\
\hline$F(21,313)$ & \multicolumn{3}{|c|}{3.20} \\
\hline Prob $>F$ & \multicolumn{3}{|c|}{0.001} \\
\hline$R^{2}$ & \multicolumn{3}{|c|}{0.1767} \\
\hline $\operatorname{Adj} R^{2}$ & \multicolumn{3}{|c|}{0.1215} \\
\hline
\end{tabular}

school) and AIDS risk perception in students. Although there has been no study on social capital and AIDS risk perception in Iran and previous studies have focused on social capital and risky behaviors in different social groups, the above finding is consistent with the results of some studies from other countries. For example, Bhattacharya in a qualitative study presented that social capital could be used as an ap- proach to HIV prevention [18]. The results of a study by Kohler et al. showed that social networks, especially the extent of cooperation in these networks had significant effects on the risk perception of a new behavior, including activities that lead to the transmission of HIV/AIDS [19]. In another study, Wang et al. found that social capital could enhance organizational performance and ultimately improves HIV/ AIDS prevention [20].

Our results are inconsistent with some outcomes of a study by Amin et al., who found social capital could not predict unprotected sex but has a positive association with HIV transmission and high-risk behaviors, such as sex with strangers, having several partners, injecting drug abuse, and homosexuality [21]. Moreover, our findings are consistent with the results of a study by Bagheri on a relationship between high-risk sexual behaviors and lower social capital in students [22], and Bostian who investigated a relationship between family and school social capital with drug abuse and unsafe sex in students [23]. Nevertheless, researches asserted the protective role of positive networks and relationships in the school in preventing unsafe sexual behaviors, alcohol, and drug abuse [24].

According to Hirschi theory of social control, adolescents who have more social connections with their families are less likely to engage in social anomalies and high-risk behaviors [25]. Similarly, Han and Kaylor showed that there was a significant negative association between family social capital with smoking, drinking, aggression, and unsafe behaviors [26]. According to previous studies, assessing the impact of social capital on people's perception about risk of $\mathrm{HIV}$, and applying preventive strategies could be a key step in reducing the spread of the disease.

Another finding of the present study was the positive association between AIDS health literacy and AIDS risk perception, which is consistent with a study of Sychareun et al. [27]. A research by Palumbo also showed that inadequate health literacy was a social barrier to access appropriate healthcare and treatment for HIV patients, and people with poor health literacy were less likely to follow instructions of healthcare professionals and had a low level of the disease risk perception [28].

Also, similar studies have shown that low health literacy is a barrier to HIV testing [29, 30]. In an explanation of the mechanism of influencing health literacy on disease risk perceptions, it can be stated that health literacy is an important factor in the relationship between physician and patient and health outcomes; therefore, having a low level of health literacy as well as lower understanding of verbal and written medical advices may have a negative impact on health status. Thus, when the ability of analyzing and understanding the effects of a disease is little, it will consequently reduce the perception of risks and potential threats.

The results of this study also demonstrated a significant relationship between both family and school dimensions of social capital with AIDS health literacy in adolescents. Similar with this result, Yang et al. showed that social capital was a strong predictor of health literacy [31]. A study in Iran also indicated a significant positive relationship between social capital and awareness about AIDS [4]. Webel 
et al. found a negative relationship between social capital and the experience of HIV symptoms among a sample from five countries [32]. Benifatemeh et al. reported a mutual relationship between social support and health literacy, and showed that social support was a strong determinant of one's health level [33]. As an analytical mechanism of impact or relationships of social capital and health literacy, Frumence found that social groups provided new ways to exchange information by creating new norms. Therefore, individuals with a stronger membership ties receive more support of the group and consequently, have a higher level of social capital. These groups can enhance health literacy and prevent diseases, such as AIDS, by applying stricter laws about respecting group norms and values as well as building trust within the group [34].

The results of regression model showed that the two variables of AIDS health literacy and family social capital had the strongest relationship with AIDS risk perceptions. The direct effects of health literacy on AIDS risk perception were greater than family social capital. It should be noted that due to a greater impact of AIDS-related health literacy, we cannot ignore the role of social capital on HIV risk perception, because family is a main source of knowledge and effective entity on individuals, especially adolescents. Therefore, enhancing parental health literacy about AIDS can promote the potential of family to reduce the burden of the disease and its adverse effects on individual and society.

This study has a limitation of cross-sectional studies, which cannot examine a causal relationship between variables. Other limitation of the study is a viewpoint of some school officials about HIV/AIDS as a taboo, which has led to some difficulties in collecting data. It is recommended that researchers in future studies investigate the AIDS health literacy in parents as well as measuring the level of social capital in people with HIV/AIDS.

\section{Conclusions}

This study shows that health literacy and social capital in a linear combination explained about $12.5 \%$ of the AIDS risk perceptions. This emphasize the increased power of visual and written analysis and understanding of adolescents, along with cohesion, respect, trust, and mutual understanding.

\section{Acknowledgments}

We would like to thank Kermanshah University of Medical Sciences for providing financial support to the present study (grant number: 95577).

\section{Conflict of interest}

The authors declare no potential conflicts of interest.

\section{References}

1. Khademi N, Reshadat S, Zanganeh A, Saeidi S, Ghasemi S, Zakiei A. Identifying HIV distribution pattern based on clustering test using GIS software, Kermanshah, Iran. HIV AIDS Rev 2016; 15: 147-152.

2. Khademi N, Reshadat S, Zangeneh A, et al. A comparative study of the spatial distribution of HIV prevalence in the metropolis of Kermanshah, Iran, in 1996-2014 using geographical information systems. HIV Med 2017; 18: 220-224.

3. Meshkati M, Hajari A, Mostajeran M, Nematolahi S, Mohammadian-Hafshejani-Hafshejani A, Hosseiny L. Knowledge and attitudes of married women referred to health centers affiliated to Isfahan University of Medical Sciences, Iran, about AIDS and related factors. Journal of Mazandaran University of Medical Sciences 2014; 23: 100-107.

4. Hoseinpour N, Sabagh S. Determining the level of knowledge of the Garmi city (Moghan) of AIDS and its relation with socioeconomic factors. Sociological Studies Journal 2013; 5: 119-141.

5. Haghdoost A, Pourkhandani A, Motaghipisheh S, Farhoudi B, Fahimifar N, Sadeghirad B. Knowledge and attitude concerning HIV/ AIDS among Iranian population: a systematic review and metaanalysis. Iranian Journal of Epidemiology 2011; 6: 8-20.

6. Shariatinia S, Fararoei M, Karimzadeh Shirazi K, Shams M. Assessment of HIV/AIDS literacy in 15-49 years old people in Yasuj and its related factors. Armaghane Danesh 2015; 19: 1082-1095.

7. Tol A, Pourreza A, Tavasoli E, Rahimi Foroshani A. Determination of knowledge and health literacy among women with type 2 diabetes in teaching hospitals of TUMS. Journal of Hospital 2012; 11: 45-52.

8. Kalichman SC, Pope H, White D, et al. Association between health literacy and HIV treatment adherence: further evidence from objectively measured medication adherence. Journal of the International Association of Physicians in AIDS Care 2008; 7: 317-323.

9. Graham J, Bennett IM, Holmes WC, Gross R. Medication beliefs as mediators of the health literacy-antiretroviral adherence relationship in HIV-infected individuals. AIDS Behav 2007; 11: 385-392.

10. Rafieian M, Parsaeian A. The assessment of risk perception spatial pattern segregated neighborhoods in Yazd city. J Crisis Management 2016: 37-46.

11. Renner B, Schupp HT. Gesundheitliche Risiken: Wahrnehmung und Verarbeitung. In: Schwarzer R (ed.). Gesundheitspsychologie. Enzyklopädie der Psychologie. Göttingen: Hogrefe; 2005. pp. $173-$ 193.

12. Zakiei A, Rajabi Gilan N, Reshadat S, Ghasemi SR. The role of social trust in explaining psychological disorders in Kermanshah, Iran. Journal of Mazandaran University of Medical Sciences 2015; 25: 119-127.

13. Rjabi Gilan N, Ghaeemi S, Reshadat S, Rajabi Gilan S. The relationship between social capital and health-related quality of life among teachers. J Adv Med Biomed Res 2013; 21: 95-107.

14. Chalabi M, Mobaraki M. Analysis of the relationship between social capital and crime in the macro and micro levels. Journal of Sociology 2011; 11: 34-57.

15. Golchin M, Haidary AH. Interpersonal violence and social capitalin family and school. Social Issues in Iran 2011; 3: 177-212.

16. Arabi M, Rakhshi M, Heidarzadeh M, Ghahramanian A. Knowledge and attitude of female high school students in relation to AIDS in Bonab. Journal of Holistic Nursing And Midwifery 2013; 23: 45-53.

17. Rezaei M, Zakiei A, Reshadat S, Ghasemi SR. The role of individual and personality factors in controlling risky behaviours related to AIDS: proposing a causal model. Personal Ment Health 2017; 11: 51-63.

18. Bhattacharya G. Social capital and HIV risks among acculturating Asian Indian men in New York City. AIDS Educ Prev 2005; 17: 555 567.

19. Kohler HP, Behrman JR, Watkins SC. Social networks and HIV/ AIDS risk perceptions. Demography 2007; 44: 1-33. 
20. Wang D, Xu X, Mei G, et al. The relationship between core members' social capital and perceived and externally evaluated prestige and cooperation among HIV/AIDS-related civil society organizations in China. Eval Health Prof 2017; 40: 61-78.

21. Amin I. Social capital and sexual risk-taking behaviors among older adults in the United States. J Appl Gerontol 2016; 35: 982-999.

22. Bagheri Yazdi H. The relationship between social capital and risk taking behaviors in undergraduate students of Tehran's Allamah Tabatabaii University. Social Welfare Quarterly 2011; 11: 223-250.

23. Boostani D. Social capital and risky behavior: case study of high school students of Kerman. Journal of Social Sciences (Faculty of Literature and Human Sciences, Mashhad) 2012; 1: 1-31.

24. Waylen A, Stallard N, Stewart-Brown S. Parenting and health in mid-childhood: a longitudinal study. Eur J Public Health 2008; 18: 300-305.

25. Jones JC. A study of the association between risk-taking, neighborhood social capital and life satisfaction among adolescent girls. California State University, Sacramento 2013.

26. Han Y, Grogan-Kaylor A. Social capital and the onset of health-risk behaviors among Korean youths. Social Work Research 2015; 39: 199-211.

27. Sychareun V, Thomsen S, Chaleunvong K, Faxelid E. Risk perceptions of STIs/HIV and sexual risk behaviours among sexually experienced adolescents in the Northern part of Lao PDR. BMC Public Health 2013; 13: 1126.

28. Palumbo R. Discussing the effects of poor health literacy on patients facing HIV: a narrative literature review. Int J Health Policy Manag 2015; 4: 417.

29. Barragán M, Hicks G, Williams MV, Franco-Paredes C, Duffus W, Del Rio C. Low health literacy is associated with HIV test acceptance. J General Intern Med 2005; 20: 422-425.

30. Reisi M, Mostafavi F, Javadzade H, Mahaki B, Tavassoli E, Sharifirad G. Communicative and critical health literacy and self-care behaviors in patients with type 2 diabetes. Iranian Journal of Diabetes and Metabolism 2016; 14: 199-208.

31. Yang HH, Kuo SC, Yang HJ, Yu JC. Social capital and health literacy in Taiwan. Health 2013; 5: 898.

32. Webel AR, Wantland D, Rose CD, et al. A cross-sectional relationship between social capital, self-compassion, and perceived HIV symptoms. J Pain Sympt Manag 2015; 50: 59-68.

33. Benifatemeh H, Aghdam MBA, Shahamfar J, Abdi B. Health and its social determinants: a study on health inequalities among Tabriz Citizens. J Appl Soc 2014; 24: 73-90.

34. Frumence G. The role of social capital in HIV prevention: Experiences from the Kagera region of Tanzania: Department of Public Health and Clinical Medicine, Umeå University; 2011. 